\title{
A Greener Approach for Synthesis of Functionalized Polyolefins by Introducing Reactive Functionality into Ethylene Copolymers
}

\author{
Wannida Apisuk1, Ken Tsutsumi1, Hyun Joon Kim², Dong Hyun Kim² ${ }^{2}$, Kotohiro Nomura ${ }^{{ }^{*}}$ \\ ${ }^{1}$ Department of Chemistry, Tokyo Metropolitan University, Tokyo, Japan \\ ${ }^{2}$ Korea Institute of Industrial Technology, Ansan, Republic of Korea \\ Email: "dhkim@kitech.re.kr, ${ }^{*}$ ktnomura@tmu.ac.jp
}

Received 27 May 2014; revised 27 June 2014; accepted 26 July 2014

Copyright (C) 2014 by authors and Scientific Research Publishing Inc.

This work is licensed under the Creative Commons Attribution International License (CC BY).

http://creativecommons.org/licenses/by/4.0/

(c) (i) Open Access

\begin{abstract}
Recent successful examples for synthesis of new polyolefins containing (polar) functionalities by adopting the approaches by controlled incorporation of reactive functionalities (and the subsequent introduction of polar functionalities under mild conditions) by coordination polymerization in the presence of transition metal complex catalysts have been described. Related methods (such as direct copolymerization of olefin with polar monomer using living radical or coordination insertion methods) have also been demonstrated for comparison. Our recent efforts for precise synthesis of polyolefins containing polar functionalities by efficient incorporation of reactive functionality by copolymerization of ethylene with nonconjugateddiene $(1,7$-octadiene, vinylcyclohexene etc.) or divinyl-biphenyl using nonbridged half-titanocene [ex. $\mathrm{Cp}^{\prime} \mathrm{TiCl}_{2}\left(\mathbf{O}-2,6-{ }^{-i} \mathrm{Pr}_{2} \mathrm{C}_{6} \mathrm{H}_{3}\right)$, $\mathrm{Cp}^{\prime}=\mathrm{C}_{5} \mathrm{Me}_{5},{ }^{t} \mathrm{BuC}_{5} \mathrm{H}_{4}$ etc.] catalysts have been introduced.
\end{abstract}

\section{Keywords}

Fine Polyolefin, Incorporation of Reactive Functionality, Copolymerization

\section{Introduction: Background}

Polyolefin has been one of the most important commercial synthetic plastics in our daily life, and the market capacity is still increasing even in the conventional polymers such as polyethylene [HDPE (High Density Poly-

${ }^{*}$ Corresponding authors.

How to cite this paper: Apisuk, W., Tsutsumi, K., Kim, H.J., Kim, D.H. and Nomura, K. (2014) A Greener Approach for Synthesis of Functionalized Polyolefins by Introducing Reactive Functionality into Ethylene Copolymers. Green and Sustainable Chemistry, 4, 133-143. http://dx.doi.org/10.4236/gsc.2014.43018 
ethylene), LLDPE (Linear Low Density Polyethylene)], polypropylene (PP). Considerable attention has been paid to produce new polymers with specified functions called "fine polyolefins" exemplified as COC (cyclic olefin copolymer) etc., and design of the efficient metal complex catalysts plays an important key for the success [1]-[23]. Precise control in the copolymerization is an important method that usually allows an alteration of the (physical, mechanical, and electronic) properties by varying the ratio of individual components. The catalysts exhibiting high activities with better comonomer incorporations are thus very important.

Precise, efficient synthesis of polyolefins containing polar functionalities by controlled polymerization attracts considerable attention [20]-[30] especially because of their promising amphiphilic nature. Two strategies 1) direct copolymerization with functionalized (polar) monomers (Scheme 1 and Scheme 2) post polymerization modification (Scheme 2) are commonly employed for this purpose.

\section{1) Direct copolymerization approaches}

\section{a) Free radical copolymerization (conventional)}

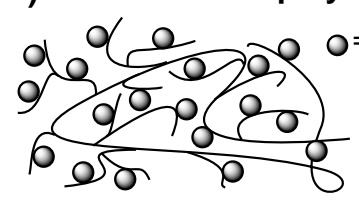

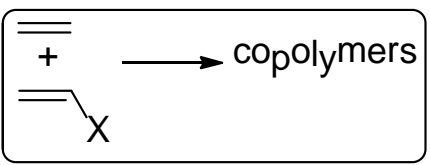

(1) Required ultra high ethylene pressure, high temperature

(2) Highly branched structure by radical migration

(3) Diff icult to control composition, molecular weight etc.

b) Metal catalyzed coordination insertion copolymerization

b-1) Late transition metal catalysts (Pd etc.)
Chainwalking, branching by accompanied isomerization<smiles>[C+]CC(C=C)=[P+]1NCCCN1</smiles>

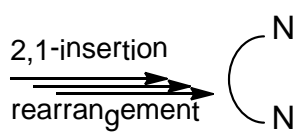<smiles>N</smiles><smiles>CC1=CCC[Te+](=O)C1</smiles>
(P) dormant<smiles>C#CC1CN[P+](C=C)(C([O])CCC(=O)OC)NC1</smiles>

$\mathrm{R} R$<smiles>[R]P1c2ccccc2S(=O)(=O)O[R]1([Y])C</smiles>

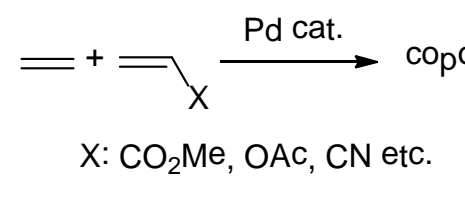
copolymers (linear)

Difficulty for obtainment of high MW ${ }^{\mathrm{co}} \mathrm{p} \mathrm{Oly}$ mers with high comonomer contents

b-2) Copolymerization with protected comonomer by early transition metal catalysts

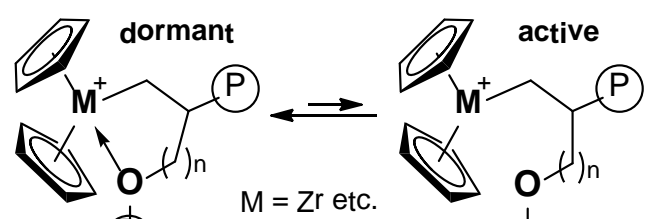

Presence of interaction between functional grou $_{p}$ and metal center

(1) Decrease in the activity and MW u $\mathrm{p}^{\mathrm{On}}$ increasing the comonomer content

(2) Difficulty for obtainment of copolymers with high comonomer contents

(R) $R=$ protecting group

(R) Protection should be required to avoid the deactivation

c) Living radical copolymerization (ATRP, Nitroxide, RAFT etc.)

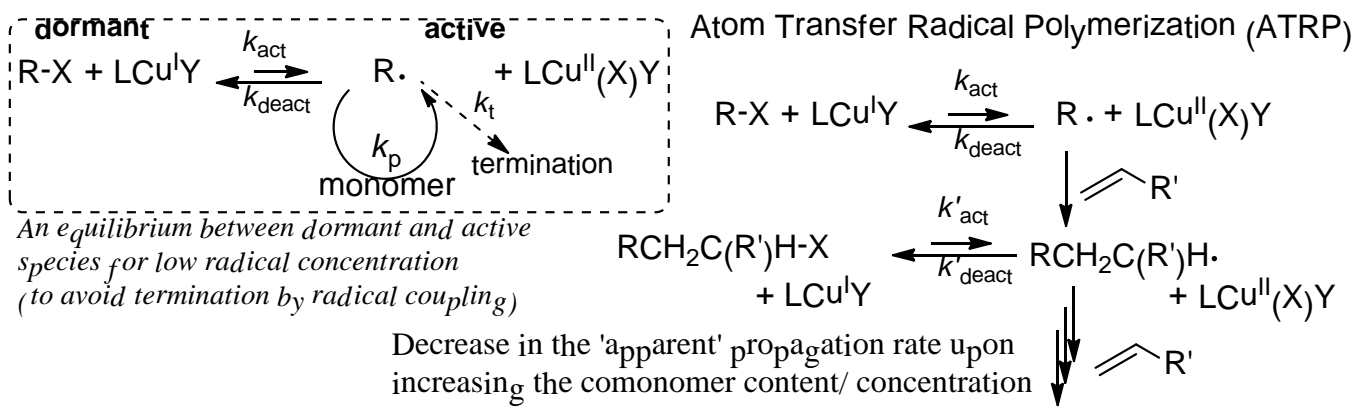

Scheme 1. Approaches for syntheses of functionalized polyolefins by “direct” copolymerization. 


\section{2) Post functionalization approaches}

a) Free radical functionalization (grafting) of polyolefins (conventional)

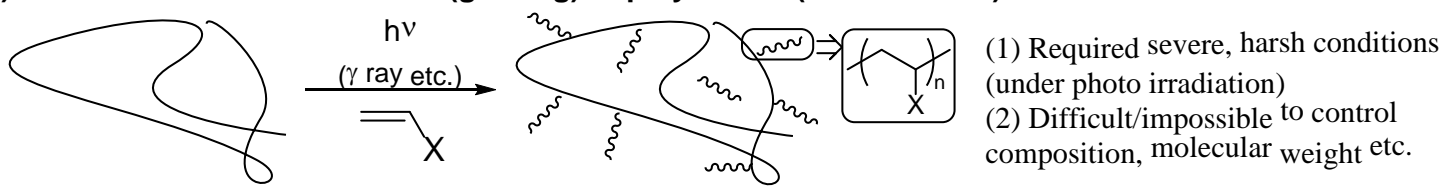

b) Transition metal catalyzed direct functionalization (C-H bond activation)

b-1) Regiospecific functionalization and subsequent oxidation

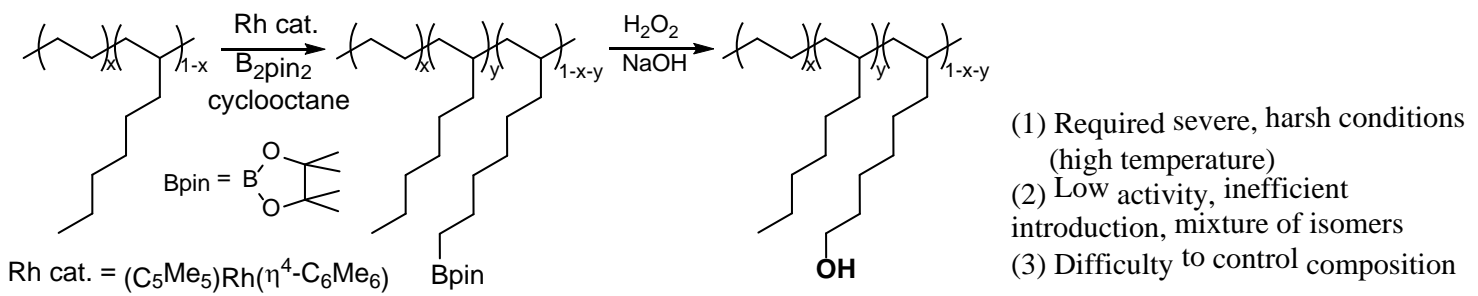

b-2) Alkane transfer dehydrogenation

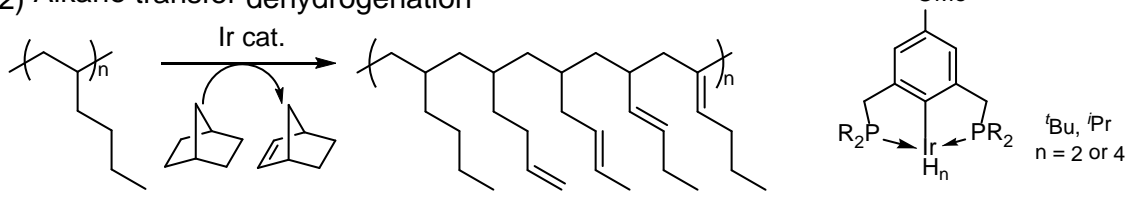

c) Controlled incorporation of reactive functionalities

(by transition metal catalyzed coordination polymerization)

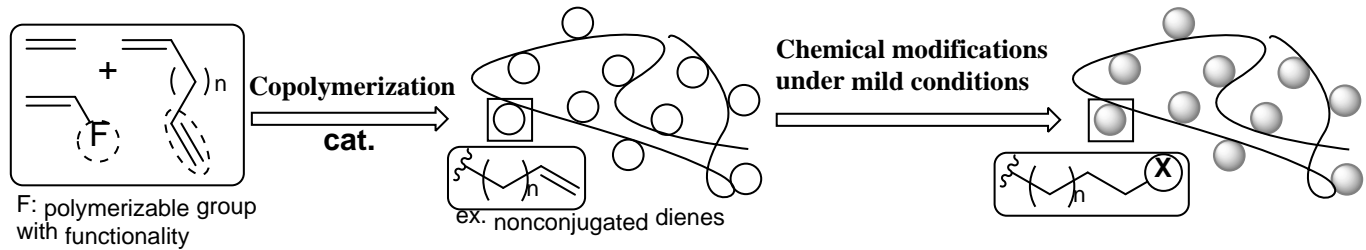

Possible: precise control of MW and contents, introduction of functionalities via chemical modifications

Required: designing efficient catalysts (exclusive selectivity, activity)!

Scheme 2. Synthesis of functionalized polyolefins by “post modification” approaches.

However, the conventional radical copolymerization (Scheme 1(a), ex. ethylene/vinyl acetate copolymerization) requires both ultrahigh pressure (ca. $1000 \mathrm{~atm}$ ) and temperature, and the resultant polymers are highlybranched random copolymers. A significant decrease in the catalytic activities and/or decomposition of the catalytically-active species due to the catalyst poisoning and interaction of centered metal with functionalized monomers (generating adducts) should be present in transition metal catalyzed coordination insertion copolymerization (Scheme 1(b)). Drastic decrease in the "apparent” propagation rate was observed in the (Cu catalyzed) atom transfer radical polymerization (ATRP) due to the unfavored equilibrium between dormant and active species (Scheme 1(c)). Preparation of the copolymer with high olefin (ethylene, propylene) content by adopting the living radical copolymerization is difficult, because the equilibrium shift to the left (dormant) upon increasing olefin contents. The direct copolymerization using Pd catalysts containing so called "posphino-sulfonate" ligands afforded low molecular weights, and more efficient catalysts are thus highly desired at this stage [25] [26]. The conventional post-modification approach (introduced as the second approach, Scheme 2), still faces difficulties, because only limited chemistry like a free radical grafting reaction is available to activate the completely saturated aliphatic molecular structure (Scheme 2(a)) [27] [28].

Recently, another new approach, controlled incorporation of a reactive moiety that introduces polar functionalities through chemical modification (Scheme 2(c)), has been considered [21]-[23] [29] [30]. Progresses on this approach especially our recent successful demonstrations for efficient controlled introduction of polar functionalities into polyolefins by copolymerization with nonconjugateddienes have also been introduced. 


\section{Synthesis of Polyolefins Containing Polar Functionalities by Controlled Introduction of Reactive Functionalities}

Recently, an approach on controlled incorporation of a reactive moiety that introduces functionalities through chemical modification (Scheme 2(c)) [21]-[23] [29] [30] has been considered as an alternative route. A known classic model of this approach is the introduction of unsaturation as exemplified by using 5-ethylidene-2-norbornene, 1,4-hexadiene, and dicyclopentadiene (but showed inefficient incorporations in the copolymerization by ordinary catalysts) [20] [31]. Introduction of unsaturatedolefinic double bond into the side chain can be possible by adopting thecopolymerizatioin of ethylene with 7-methyl-1,6-octadiene (MOD, Scheme 3) [29] [30] [32], especially due to a difference in the reactivity of two olefinic double bonds (terminal vs trisubstituted). However, their incorporations by the ordinary catalysts (metallocenes etc.) were inefficient, affording (co)polymers with low molecular weights as well as rather broad molecular weight distributions. We reported that copolymerizations of ethylene with 7-methyl-1,6-octadiene (MOD) by $\mathrm{Cp}^{*} \mathrm{TiCl}_{2}\left(\mathrm{O}-2,6-{ }^{i} \mathrm{Pr}_{2} \mathrm{C}_{6} \mathrm{H}_{3}\right)$ (1)- $\mathrm{MAO}$ catalyst system afforded high molecular weight unsaturated poly(ethylene-co-MOD)s not only with high MOD contents, but also with exclusive incorporation of monoolefins (without incorporating trisubstituted olefin) [32]. The MOD contents in the resultant copolymers were thus closely related to those in the ethylene/1-octene copolymerizations under the similar conditions.

For introduction of more reactive functionality (terminal olefin) into the side chain for the efficient functionalization process under mild conditions, use of nonconjugateddiene like 1,5-hexadiene (HD) for synthesis of functionalized polyolefin by the favored repeated HD insertion has been considered [33] [34], although most of the reported examples using ordinary catalysts such as zirconocene (exemplified as $\mathbf{3}$ and $\mathbf{4}$, Scheme 4), titanocene, half-zirconocene, and others favored cyclopolymerization incorporating methylene-1,3-cyclopentane unit (Scheme 4, route A). The approach should introduce promising possibilities like, incorporation of terminalolefinic double bond (route B) that would introduce polar functionality in a controlled manner by chemical modification under mild conditions.

Polymerizations of $\mathrm{HD}$ by $\mathrm{Cp}^{*} \mathrm{TiCl}_{2}(\mathrm{OAr})(\mathbf{1}),\left[\mathrm{Me}_{2} \mathrm{Si}(\text { indenyl })_{2}\right] \mathrm{ZrCl}_{2}$ (3) exhibited the remarkable catalytic activities, and the resultant poly(HD)s were insoluble [33] [34]. Based on the DSC thermograms (sole glass transition temperature), ${ }^{13} \mathrm{C}$ CPMAS spectra, and the dynamic mechanical analysis (DMA), 1 favored repeated 1,2insertion affording polymers containing olefinic double bond in the side chain (uniform distributions), whereas the polymerization by $3, \mathrm{Cp}_{2} \mathrm{ZrCl}_{2}(4)$ favored cyclization under the same conditions.

$\left[\mathrm{Me}_{2} \mathrm{Si}\left(\mathrm{C}_{5} \mathrm{Me}_{4}\right)\left(\mathrm{N}^{t} \mathrm{Bu}\right)\right] \mathrm{TiCl}_{2}$ (2) showed low activities with favored repeated insertion, affording high molecular weight poly(HD)s which possessed internal olefinic double bonds by accompanied isomerization [34].

Note that exclusive repeated insertion of 1,7-octadiene (OD) could be achieved in OD polymerization using 1-MAO catalyst, affording polymers containing terminal olefinic double bonds in the side chain [35]. Selectivity of the repeated insertion (percentage of the double bond, hexenyl group, based on the OD insertion) was affected by the OD concentration employed, but the selectivity was high even under low OD concentration [36]. The observed higher selectivity in the OD polymerization than that in the HD polymerization would be considered as the difference of the proposed intermediate in which the other olefin coordinates to Ti after HD or OD insertion (formation of 5- or 7-membered ring after cyclization).

Moreover, the copolymerizations of OD with 1-octene (OC) afforded high molecular weight copolymers with uniform molecular weight distributions, and the OD contents (degree of hexenyl group) estimated by ${ }^{1} \mathrm{H}$ NMR spectra could be varied by the OD/OC feed ratio [35]. The resultant copolymers were treated with 9-BBN and
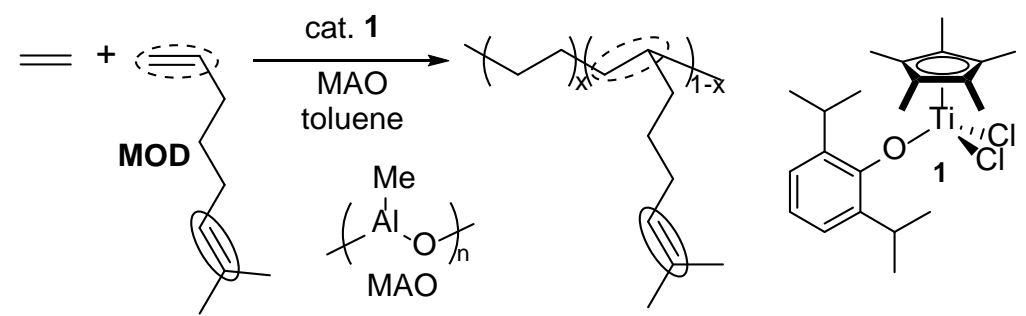

Scheme 3. Synthesis of poly(ethylene-co-7-methyl-1,6-octadiene) prepared by Cp* $\mathrm{TiCl}_{2}\left(\mathrm{O}-2,6-{ }^{i} \mathrm{Pr}_{2} \mathrm{C}_{6} \mathrm{H}_{3}\right)$ (1)-methylaluminoxane (MAO) catalyst system [32]. 


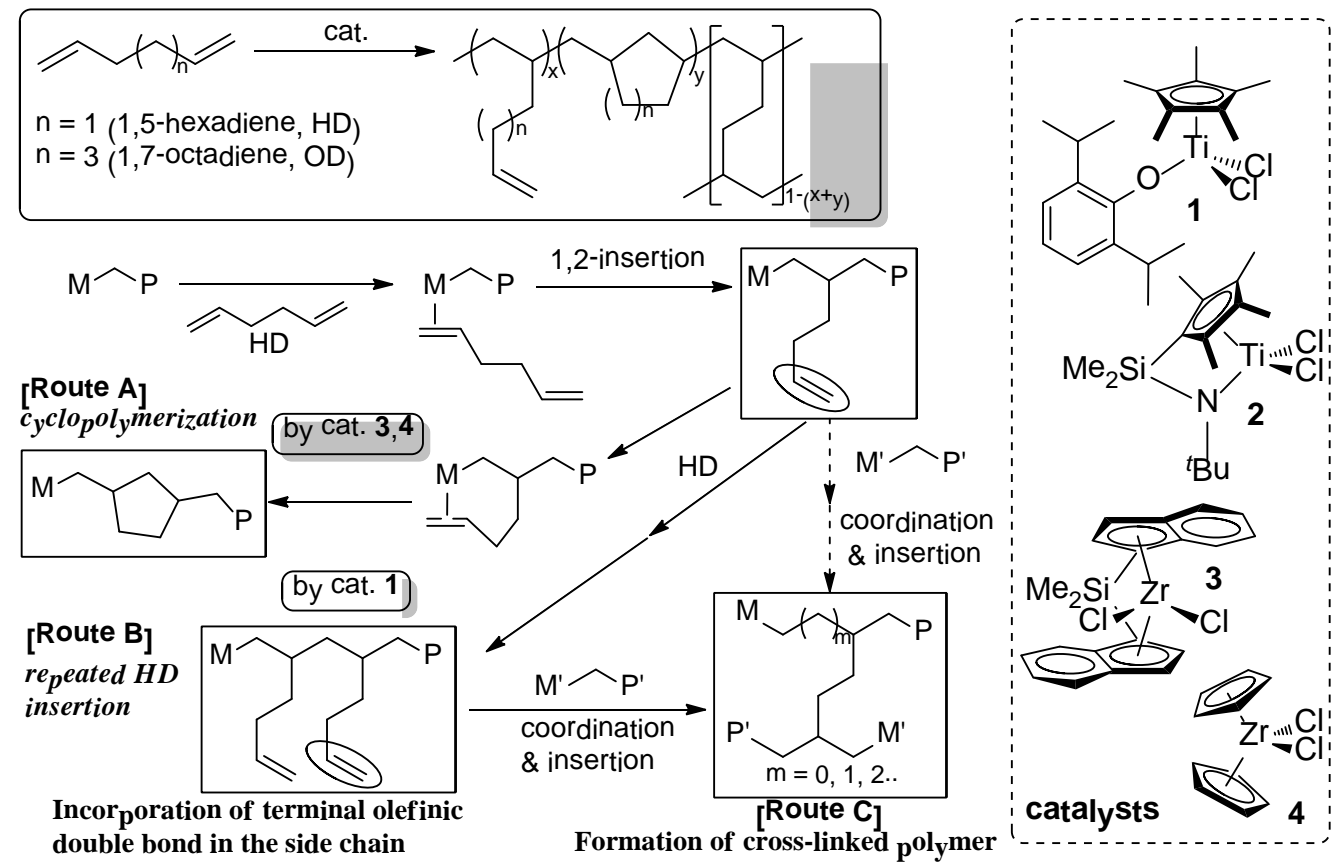

Scheme 4. Basic scheme for polymerization of nonconjugateddiene (1,5-hexadiene, HD) [33] [34].

then $\mathrm{NaOH} / \mathrm{H}_{2} \mathrm{O}_{2}$ aq. to givepoly $\{$ OC-co-(7-octen-1-ol) $\}$ exclusively (98.9\%) without decrease/increase in the $M_{\mathrm{n}}$ value [35]. The OH group in the copolymers was further treated with $\mathrm{AlEt}_{3}$, and was then added $\varepsilon$-caprolactone (CL) to afford the graft copolymers, poly\{OC-co-(7-octan-1-ol\}-graft-poly(CL), via Al-alkoxide initiated ring-opening polymerization (ROP, Scheme 5).

Copolymerization of ethylene with OC, OD were thus conducted, affording poly(ethylene-co-OC-co-OD)s containing olefinic double bond in the side chain (Scheme 6) [35]. Note that remarkable activities (activity: 29,400 - 102,600 kg-polymer/mol-Ti·h) were also observed in the copolymerization, even in syntheses of the copolymers with high OC/OD contents (OC+OD total 37.6 - 43.8 mol\%). Also note that the resultant copolymers possessed high molecular weights with unimodal molecular weight distributions.

Introduction of OD in ethylene/styrene copolymer could be achieved using aryloxo-modified half-titanocenes, Cp' $\mathrm{TiCl}_{2}\left(\mathrm{O}-2,6-{ }^{i} \mathrm{Pr}_{2} \mathrm{C}_{6} \mathrm{H}_{3}\right)$ [Cp' = $\mathrm{Cp}^{*}$ (1), ${ }^{t} \mathrm{BuC}_{5} \mathrm{H}_{4}$ (5), 1,2,4- $\mathrm{Me}_{3} \mathrm{C}_{5} \mathrm{H}_{2}$ (6)], affording high molecular weight polymers with unimodal molecular weight distributions (Table 1) [37]. The initial comonomer concentration affected both the catalytic activity and the comonomer contents [37]. Complex 6 showed the best catalyst performance in term of both the activity and the comonomer incorporation. The microstructure for poly(ethylenecostyrene-co-OD) showed the clear resonance ascribed to the vinyl carbon in the resultant polymers [37]. Moreover, no resonance ascribed to the cyclization of OD was observed, indicating that the polymerization proceeded with notable selectivity of OD repeated insertion, affording polymers containing terminal olefinic double bond in the side-chain, as demonstrated previously [35]. The present results should introduce a new promising approach for synthesis of new polyolefins.

In Scheme 7, the copolymerizations of ethylene with vinylcyclohexene (VCHen), commercially produced by dimerization of butadiene, proceeded via vinyl addition affording high molecular weight copolymers containing cyclohexenyl side chains (with uniform compositions as well as with unimodal molecular weight distributions) accompanied with certain degree of side reaction (via intra-molecular cyclization after VCHen insertion) [38]. This approach could be possible, because both $\mathrm{Cp} * \mathrm{TiCl}_{2}\left(\mathrm{O}-2,6-{ }^{i} \mathrm{Pr}_{2} \mathrm{C}_{6} \mathrm{H}_{3}\right)(\mathbf{1})$ and $\mathrm{CpTiCl}_{2}\left(\mathrm{~N}=\mathrm{C}^{t} \mathrm{Bu}_{2}\right)$ (7) exhibited efficient vinylcyclohexane (VCH) incorporation in the ethylene/VCH copolymerization [39], as well as exhibited negligible comonomer incorporation in ethylene/cyclohexene copolymerization [40]. The Cp-ketimide analogue (7) showed the best catalyst performance in terms of both the activity and the selectivity (lowest degree of the subsequent intra-molecular cyclization). Quantitative epoxidation of the olefinic double bonds in the resultant copolymer could be achieved by using $m$-chloroperbenzoic acid under mild conditions; a facile, precise synthesis of functionalized polyolefin can be demonstrated by adopting this approach. 


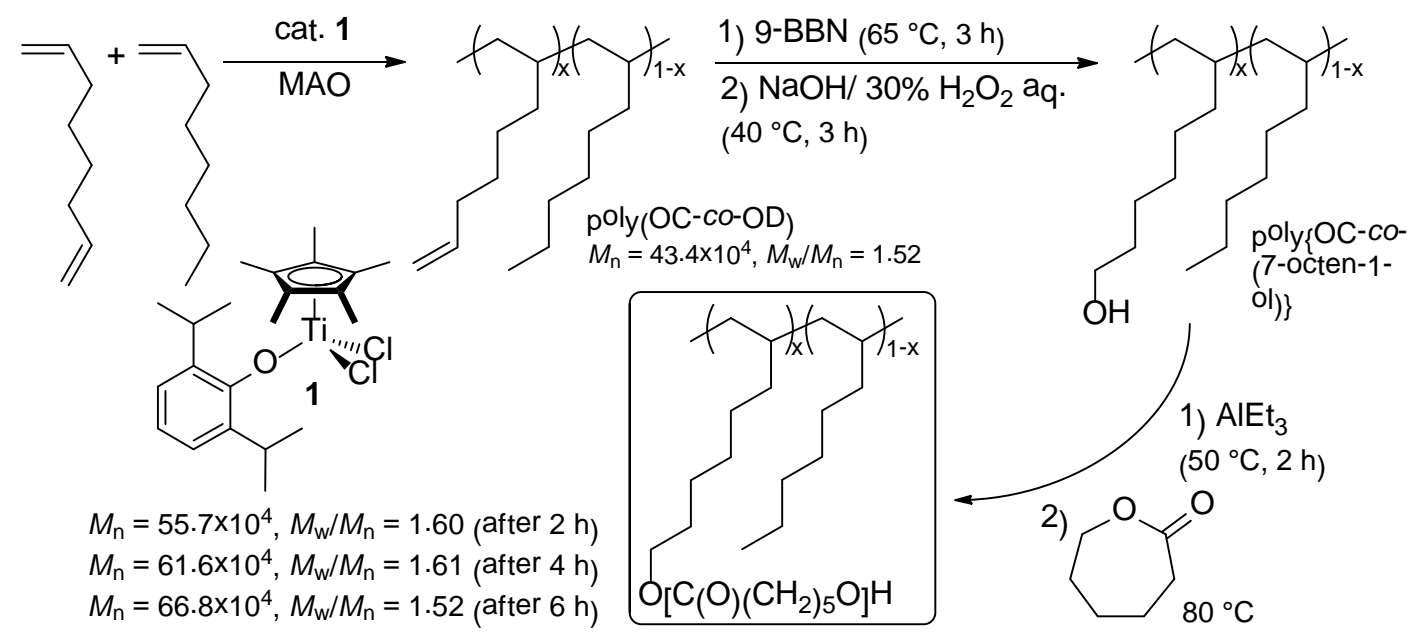

Scheme 5. Controlled introduction of polarfunctionality into polyolefins, poly(1-octene-co-1,7-octadiene) [35].

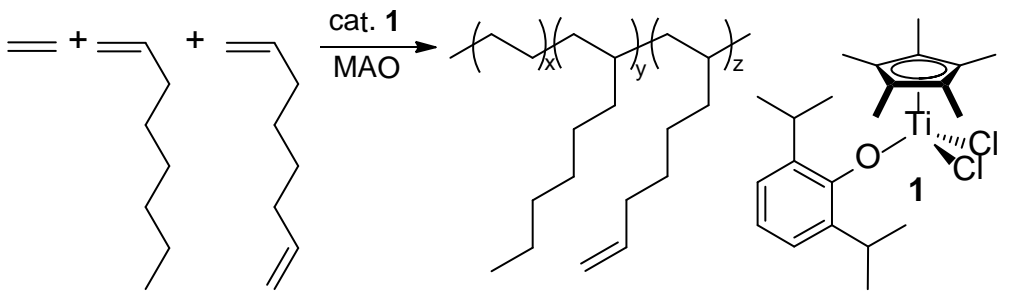

Scheme 6. Copolymerization of ethylene with 1-octene, 1,7-octadiene [35].

Table 1. Terpolymerization of ethylene and styrene (St) with 1,7-octadiene (OD) by $\mathrm{Cp}^{\prime} \mathrm{TiCl}_{2}\left(\mathrm{O}-2,6-{ }^{i} \mathrm{Pr}_{2} \mathrm{C}_{6} \mathrm{H}_{3}\right)\left[\mathrm{Cp}\right.$ ' $=\mathrm{Cp}^{*}$ (1), ${ }^{t} \mathrm{BuC}_{5} \mathrm{H}_{4}$ (5), 1,2,4- $\left.\mathrm{Me}_{3} \mathrm{C}_{5} \mathrm{H}_{2}(\mathbf{6})\right]$ - MAO systems [37].

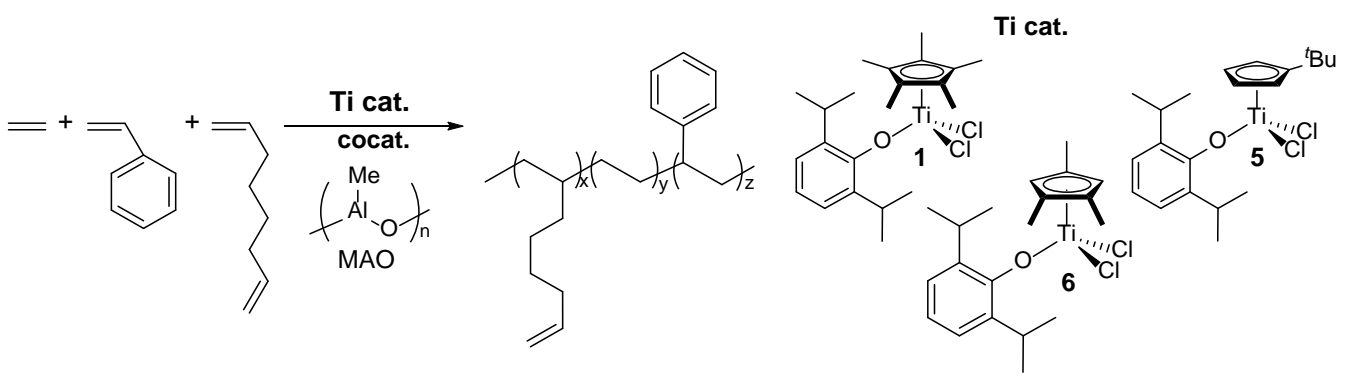

\begin{tabular}{|c|c|c|c|c|c|c|}
\hline cat. & \multirow{2}{*}[\mathrm{St}]{$_{0} /[\mathrm{OD}]_{0} /[\mathrm{E}]_{0}^{a}$} & activity & $\mathrm{St}^{b}$ & $\mathrm{OD}^{b}$ & $M_{\mathrm{n}}^{c}$ & $M_{\mathrm{w}}$ \\
\hline$(\mu \mathrm{mol})$ & & kg-polymer/mol-Ti·h & $/ \mathrm{mol} \%$ & $/ \mathrm{mol} \%$ & $\times 10^{-5}$ & $/ M_{\mathrm{n}}^{c}$ \\
\hline $1(0.2)$ & 0.8/0.3/1.0 & 3530 & 6.9 & 5.2 & 2.15 & 1.65 \\
\hline $5(0.2)$ & $0.8 / 0.3 / 1.0$ & 5490 & 15.2 & 7.1 & 1.96 & 2.23 \\
\hline $6(0.1)$ & $0.8 / 0.3 / 1.0$ & 9910 & 18.2 & 7.6 & 1.97 & 2.05 \\
\hline $6(0.2)$ & $1.2 / 0.3 / 1.0$ & 5500 & 22.1 & 6.5 & 2.00 & 2.00 \\
\hline $6(0.1)$ & $0.4 / 1.2 / 1.0$ & 15700 & 5.2 & 18.4 & 0.71 & 2.43 \\
\hline
\end{tabular}

An efficient introduction of vinyl group into poly(ethylene-co-styrene) or poly(ethylene-co-1-hexene) could be achieved by incorporation of 3,3'-divinylbiphenyl (DVBP) in terpolymerization of ethylene, styrene or 1hexene with DVBP using 1, 5 and $\mathbf{6}$ in the presence of MAO cocatalyst, affording high molecular weight polymers with unimodal distributions [41]. The ethylene/styrene copolymerization in the presence of 3,3'-diviynldiphenyl (DVBP) using 6 proceeded with high catalytic activities. The resultant polymers possessed vinyl group 


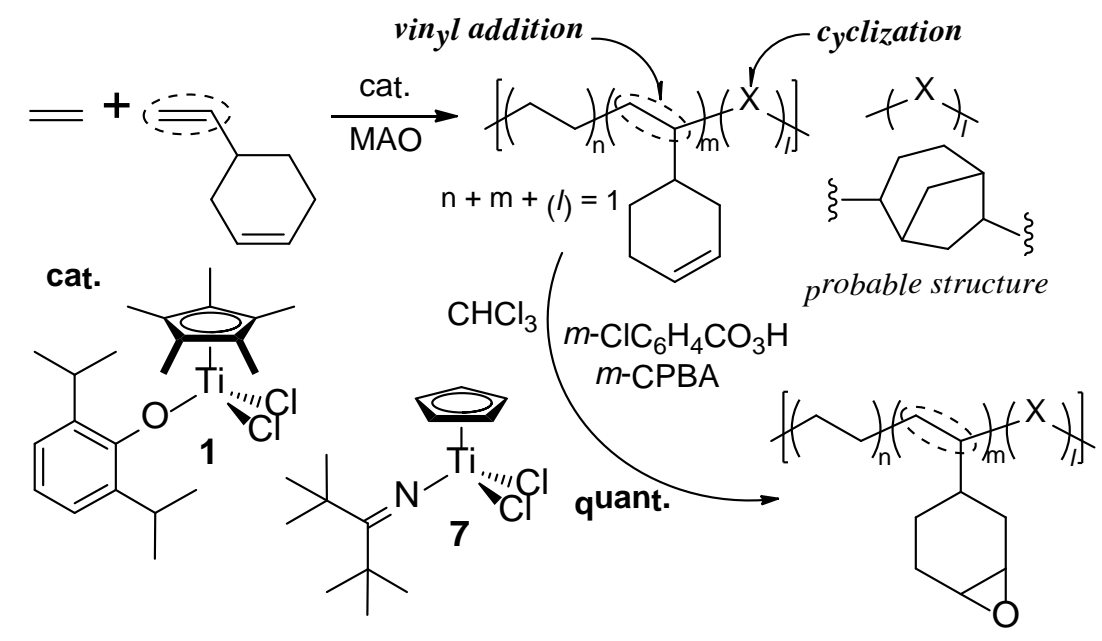

Scheme 7. Synthesis of cyclic olefin copolymers containing polar functionality [38].

in the side chain [41]. The unsaturated ethylene/styrene/DVBP polymer was subsequently polymerized via anionic polymerization using ${ }^{n} \mathrm{BuLi}$ (Scheme 8). The resultant polymer showed increases in both the $M_{\mathrm{n}}$ value and yield compared to the starting polymer and possessed unimodal molecular weight distribution [42]. An increase in the styrene content in the whole polymer $(35.9 \mathrm{~mol} \% \rightarrow 50.6 \mathrm{~mol} \%)$ as well as the intensity of the resonances ascribed to carbon of (more than) three styrene repeat units $\left(\mathrm{T}_{\beta \beta}\right)$ in the ${ }^{13} \mathrm{C}$ NMR spectrum was clearly observed [41].

Introduction of $p$-methylstyrene ( $p$-MS) should be effective for the subsequent post-modifications (to introduce additional functionality), because it has been known that the methyl group in $p$-MS can be used as the initiating fragment for anionic polymerization after treatment with s-BuLi [42] [43]. The terpolymerization of ethylene and $p$-MS with $\alpha$-olefins could be achieved using $\mathbf{1}$ and $\mathbf{5}$, affording high molecular weight polymers with unimodal molecular weight distribution (Scheme 9) [44]. Borate cocatalyst system was employed in this study, because use of MAO caused by-production of atacticpoly ( $p$-MS) in large extent under these conditions. Complex $\mathbf{1}$ showed the higher activity than $\mathbf{5}$, however, the use of $\mathbf{5}$ afforded the copolymers with higher $p$-MS and $\alpha$-olefin contents when the polymerization was proceeded under similar conditions [44]. The DSC thermograms in the polymers showed no melting temperature even with low styrene contents, and these samples do not have glass transition temperatures between $20^{\circ} \mathrm{C}$ and $290^{\circ} \mathrm{C}$. The results thus strongly suggest that the resultant polymers are terpolymers (amorphous materials) with uniform compositions.

\section{Efficient Introduction of Functional Group into Polyolefins by Direct Copolymerization Using Half-Titanocenes}

Copolymerization of ethylene with allyltrimethylsilane (ATMS) by the Cp*-aryloxo analogue (1) afforded high molecular weight copolymers with uniform molecular weight distributions (Scheme 10) [45]. Importantly, the ATMS content was relatively close to 1-pentene content in poly(ethylene-co-1-pentene) conducted under the similar conditions [45]. The Cp-ketimide analogue, $\mathrm{CpTiCl}_{2}\left(\mathrm{~N}=\mathrm{C}^{t} \mathrm{Bu}_{2}\right)(7)$ showed the less efficient ATMS incorporation under the same conditions, but exhibited much higher catalytic activity than $\mathbf{1}$, affording high molecular weight copolymers. The activities by 1,7 increased upon increasing the ATMS concentration and the ethylene pressure, and the $M_{\mathrm{n}}$ values in the copolymers were independent upon the ATMS contents. The facts are different from those in the copolymerization by ordinary metallocenes [46], whereas both the activities and the $M_{\mathrm{n}}$ values in the copolymers significantly decreased upon increasing the ATMS contents due to chain transfer byfavored $\beta$-hydrogen elimination after bulky ATMS insertion.

Vinyltrialkylsilanes should be considered as better comonomer in terms of the direct functional group introduction into polyethylene (or polypropylene) backbone as well of its use as cross-linking reagents to improve thermal properties. However, these sterically encumbered olefins are very difficult to coordinate into the metal center in ordinary metallocenes [47]. Note that both the $\mathrm{Cp}^{*}$-aryloxo analogue (1) and the Cp-ketimide analogue (7) incorporated vinyltrimethylsilane (VTMS) into polyethylene (Scheme 10), and the resultant copolymers 

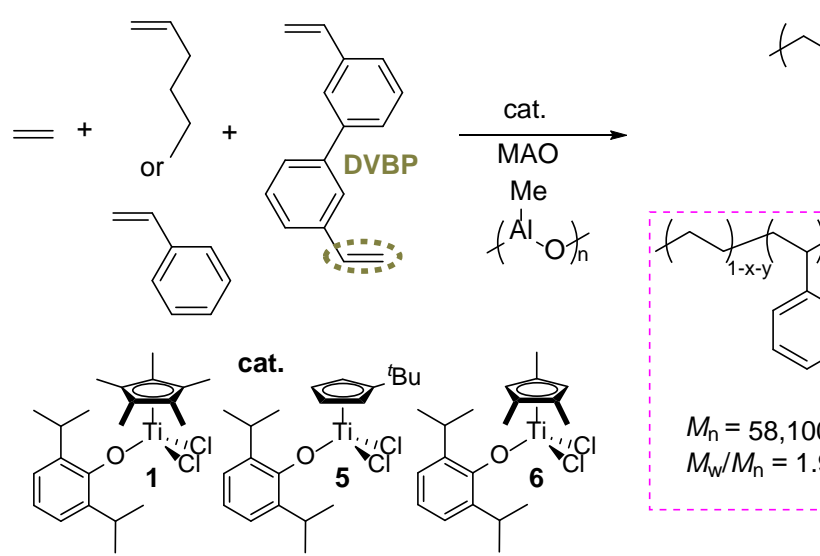

$$
\begin{aligned}
& M_{\mathrm{w}} / M_{\mathrm{n}}=1.90 \\
& \text { : }
\end{aligned}
$$

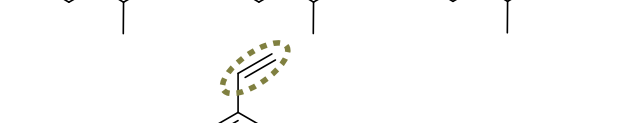<smiles>[Li]</smiles>

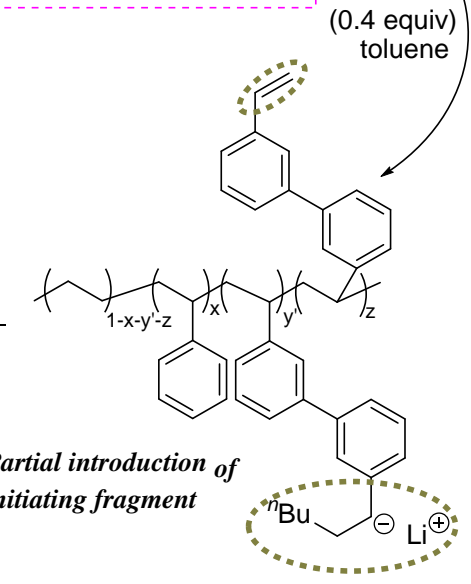

Scheme 8. Post-polymerization of poly(ethylene-co-styrene-co-DVBP) with styrene initiated by ${ }^{n} \mathrm{BuLi}[41]$.

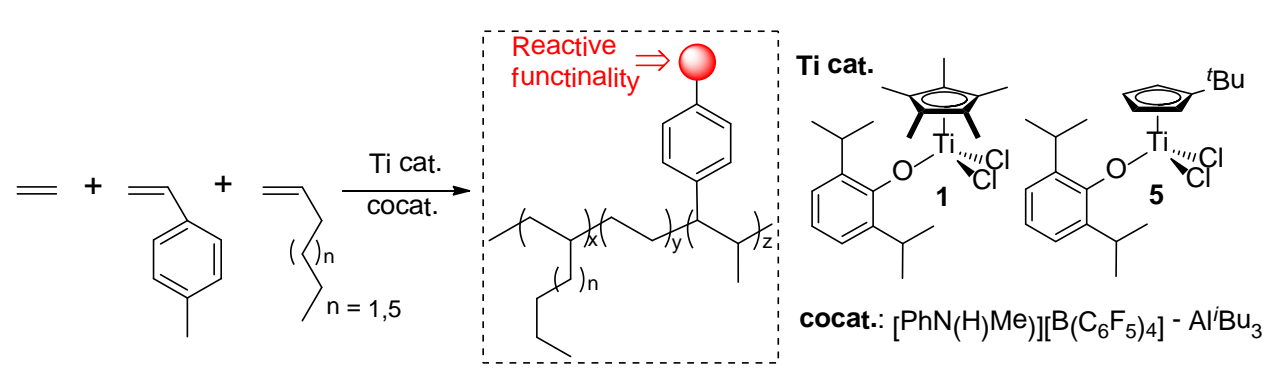

Scheme 9. Terpolymerization of ethylene and p-methylstyrene (p-MS) with $\alpha$-olefins [44].

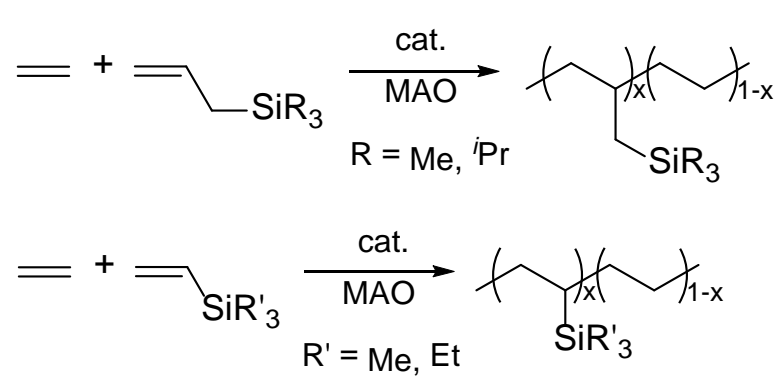

cat.<smiles>CC(C)c1cccc(C(C)C)c1O[In](Cl)Cl</smiles><smiles>CC(C)(C)C(=N[Te](Cl)(Cl)Cl)[Ge]1C=CC1</smiles>

Scheme 10. Copolymerization of ethylene with allyltrialkylsilanes [45], vinyltrialkylsilanes [48].

possessed high molecular weights with uniform molecular weight distributions [48]. Complex 7 exhibited both higher catalytic activities and better VTMS incorporations than 1: efficient synthesis of high molecular weight 
copolymers with uniform compositions could be achieved by adopting 7, although both the activity and the $M_{\mathrm{n}}$ values decreased upon increasing the VTMS contents. Later, we found that the copolymerization by the constrained geometry catalyst (2) also proceeded efficiently [49]. The attempted copolymerization using $\mathrm{Cp}_{2} \mathrm{ZrCl}_{2^{-}}$ MAO catalyst afforded linear polyethylene with low catalytic activity [48].

\section{Summary and Outlook}

Although recent progress in the living radical, metal-catalyzed coordination polymerization, and the direct terminal alkane C-H activation method offers new promising possibilities, approach on controlled incorporation of a reactive moiety that introduces polar functionalities through chemical modification has been considered as an alternative approach. An introduction of terminal olefinic double bond by repeated insertion of 1,7-octadiene (OD) without cyclization/cross linking in polymerization of OD can be achieved by using our designed catalysts, nonbridged half-titanocesnes. These enable us to prepare the functionalized polymers under mild conditions in a precise manner. The catalysts also demonstrated new possibilities for direct copolymerization of ethylene with vinyltrialkylsilanes that cannot be achieved by ordinary metallocenes. Several promising findings that should be very important from both academic and industrial viewpoints can be demonstrated; particular attention should be thus paid to explore the possibility for preparing fine polyolefins by adopting these methodologies.

\section{Acknowledgements}

Our research presented here was partly supported by Grant-in-Aid for Scientific Research (B) from the Japan Society for the Promotion of Science (JSPS, No.24350049, No.21350054), and a grant from the Fundamental R\&D Program for Core Technology of Materials funded by the Ministry of Knowledge Economy, Republic of Korea. K.N. and W.A. express their thanks to Tosoh Finechem Co. for donating MAO, and K.N. would like to express his heartfelt thanks to his former group members who contributed to the projects as the coauthors.

\section{References}

[1] Mason, A.F. and Coates, G.W. (2007) Coordination Polymerization: Synthesis of New Homo- and Copolymer Architectures from Ethylene and Propylene Using Homogeneous Ziegler-Natt Polymerization Catalysts. In: Matyjaszewski, K., Gnanou, Y. and Leibler L., Eds., Macromolecular Engineering, Wiley-VCH, Weinheim, 1, 217-248. http://dx.doi.org/10.1002/9783527631421.ch6.

[2] Brintzinger, H.H., Fischer, D., Mülhaupt, R., Rieger, B. and Waymouth, R.M. (1995) Stereospecific Olefin Polymerization with Chiral Metallocene Catalysts. Angewandte Chemie International Edition in English, 34, 1143-1170. http://dx.doi.org/10.1002/anie.199511431

[3] Kaminsky, W. (1996) New Polymers by Metallocene Catalysis. Macromolecular Chemistry and Physics, 197, 39073945. http://dx.doi.org/10.1002/macp.1996.021971201

[4] Kaminsky, W. and Arndt, M. (1997) Metallocenes for Polymer Catalysis. Advances in Polymer Science, 127, $143-187$. http://dx.doi.org/10.1007/BFb0103631

[5] Suhm, J., Heinemann, J., Wörner, C., Müller, P., Stricker, F., Kressler, J., Okuda, J. and Mülhaupt, R. (1998) Novel Polyolefin Materials via Catalysis and Reactive Processing. Macromolecular Symposia, 129, 1-28. http://dx.doi.org/10.1002/masy.19981290103

[6] McKnight, A.L. and Waymouth, R.M. (1998) Group 4 ansa-Cyclopentadienyl-Amido Catalysts for Olefin Polymerization. Chemical Reviews, 98, 2587-2598. http://dx.doi.org/10.1021/cr940442r

[7] Britovsek, G.J.P., Gibson, V.C. and Wass, D.F. (1999) TheSearch for New-Generation Olefin Polymerization Catalysts: Life beyond Metallocenes. Angewandte Chemie International Edition in English, 38, 428-447. http://dx.doi.org/1433-7851/99/3804-0429

[8] Gibson, V.C. and Spitzmesser, S.K. (2003) Advances in Non-Metallocene Olefin Polymerization Catalysis. Chemical Reviews, 103, 283-316. http://dx.doi.org/10.1021/cr980461r

[9] Bolton, P.D. and Mountford, P. (2005) Transition Metal Imido Compounds as Ziegler-Natta Olefin Polymerisation Catalysts. Advanced Synthesis \& Catalysis, 347, 355-366. http://dx.doi.org/10.1002/adsc.200404267

[10] Gladysz, J. A. (Ed.) (2000) Frontiers in Metal-Catalyzed Polymerization. Chemical Reviews, 100, 1167-1682. http://dx.doi.org/10.1021/cr000450

[11] Guan, Z. (Ed.) (2009) Metal Catalysts in Olefin Polymerization. Topics in Organometallic Chemistry, 26, 3-251.

[12] Nomura, K., Liu, J., Padmanabhan, S. and Kitiyanan, B. (2007) Nonbridged Half-Metallocenes Containing Anionic 
Ancillary Donor Ligands: New Promising Candidates as Catalysts for Precise Olefin Polymerization. Journal of Molecular Catalysis A: Chemical, 267, 1-29. http://dx.doi.org/10.1016/j.molcata.2006.11.006

[13] Nomura, K. (2009) Half-Titanocenes Containing Anionic Ancillary Donor Ligands as Promising New Catalysts for Precise Olefin Polymerization. Dalton Transactions, 41, 8811-8823. http://dx.doi.org/10.1039/B910407K

[14] Nomura, K. and Liu, J. (2011) Half-Titanocenes for Precise Olefin Polymerisation: Effects of Ligand Substituents and Some Mechanistic Aspects. Dalton Transactions, 40, 7666-7682. http://dx.doi.org/10.1039/C1DT10086F

[15] Schellenberg, J. (Ed.) (2010) Syndiotactic Polystyrene-Synthesis, Characterization, Processing, and Applications. Wiley-VCH, Hoboken.

[16] Tomotsu, N., Ishihara, N., Newman, T.H. and Malanga, M.T. (1998) Syndiospecific Polymerization of Styrene. Journal of Molecular Catalysis A: Chemical, 128, 167-190. http://dx.doi.org/10.1016/S1381-1169(97)00171-4

[17] Schellenberg, J. (2009) Recent Transition Metal Catalysts for Syndiotactic Polystyrene. Progress in Polymer Science, 34, 688-718. http://dx.doi.org/10.1016/j.progpolymsci.2009.04.002

[18] Nomura, K. (2010) Syndiotactic Polystyrene: Synthesis, Characterization, Processing, and Applications. Wiley-VCH, Hoboken, 60-91.

[19] Nomura, K. (2011) Syndiospecific Styrene Polymerization and Ethylene/Styrene Copolymerization Using Half-Titanocenes: Ligand Effects and Some New Mechanistic Aspects. Catalysis Surveys from Asia, 14, 33-49. http://dx.doi.org/10.1007/s10563-010-9086-4

[20] Chung, T.C. (2002) Functionalization of Polyolefins. Academic Press, San Diego.

[21] Boffa, L.S. and Novak, B.M. (2000) Copolymerization of Polar Monomers with Olefins Using Transition-Metal Complexes. Chemical Reviews, 100, 1479-1494. http://dx.doi.org/10.1021/cr990251u

[22] Chung, T.C. (2002) Synthesis of Functional Polyolefin Copolymers with Graft and Block Structures. Progress in Polymer Science, 27, 39-85. http://dx.doi.org/10.1016/S0079-6700(01)00038-7

[23] Chung, T.C. (2012) Functionalization of Polypropylene with High Dielectric Properties: Applications in Electric Energy Storage. Green and Sustainable Chemistry, 2, 29-37. http://dx.doi.org/10.4236/gsc.2012.22006

[24] Boaen, N.K. and Hillmyer, M.A. (2005) Post-Polymerization Functionalization of Polyolefins. Chemical Society Reviews, 34, 267-275. http://dx.doi.org/10.1039/B311405H

[25] Nakamura, A., Ito, S. and Nozaki, K. (2009) Coordination-Insertion Copolymerization of Fundamental Polar Monomers. Chemical Reviews, 109, 5215-5244. http://dx.doi.org/10.1021/cr900079r

[26] Nakamura, A., Anselment, T.M.J., Claverie, J., Goodall, B., Jordan, R.F., Mecking, S., Rieger, B., Sen, A., van Leeuwen, P.W.N.M. and Nozaki, K. (2013) Ortho-Phosphinobenzenesulfonate: A Superb Ligand for Palladium-Catalyzed Coordination-Insertion Copolymerization of Polar Vinyl Monomers. Account of Chemical Research, 46, 1438-1449. http://dx.doi.org/10.1021/ar300256h

[27] Doak, K.W. (1986) Low Density Polyethylene (High Pressure). In: Mark, H.F., Ed., Encyclopedia of Polymer Science and Engineering, John Wiley \& Sons, New York, 6, 386-429.

[28] Moad, G. (1999) The Synthesis of Polyolefin Graft Copolymers by Reactive Extrusion. Progress in Polymer Science, 24, 81-142. http://dx.doi.org/10.1016/S0079-6700(98)00017-3

[29] Nomura, K. and Kitiyanan, B. (2008) Recent Progress in Precise Synthesis of Polyolefins Containing Polar Functionalities by Transition Metal Catalysis. Current Organic Synthesis, 5, 217-226. http://dx.doi.org/10.2174/157017908785133456

[30] Nomura, K. (2010) New Approaches in Precise Synthesis of Polyolefins Containing Polar Functionalities by OlefinCopolymerizations Using Transition Metal Catalysts. Journal of Synthetic Organic Chemistry, Japan, 68, 1150-1158. http://dx.doi.org/10.5059/yukigoseikyokaishi.68.1150

[31] Chung, T.C., Lu, H.L. and Li, C.L. (1994) Synthesis and Functionalization of Unsaturated Polyethylene: Poly(ethylene-co-1,4-hexadiene). Macromolecules, 27, 7533-7537. http://dx.doi.org/10.1021/ma00104a005

[32] Itagaki, K., Fujiki, M. and Nomura, K. (2007) Effect of Cyclopenta Dienyl and Anionic Donor Ligands on Monomer Reactivities in Copolymerization of Ethylene with 2-Methyl-1-pentene by Nonbridged Half-Titanocenes-Cocatalyst Systems. Macromolecules, 40, 6489-6499. http://dx.doi.org/10.1021/ma0700429

[33] Nomura, K., Hatanaka, Y., Okumura, H., Fujiki, M. and Hasegawa, K. (2004) Polymerization of 1,5-Hexadiene by the Nonbridged Half-Titanocene Complex-MAO Catalyst System: Remarkable Difference in the Selectivity of Repeated 1,2-Insertion. Macromolecules, 37, 1693-1695. http://dx.doi.org/10.1021/ma049938t

[34] Nomura, K., Takemoto, A., Hatanaka, Y., Okumura, H., Fujiki, M. and Hasegawa, K. (2006) Polymerization of 1,5Hexadiene by Half-Titanocenes-MAO Catalyst Systems: Factors Affecting the Selectivity for the Favored Repeated 1,2-Insertion. Macromolecules, 39, 4009-4017. http://dx.doi.org/10.1021/ma0604892 
[35] Nomura, K., Liu, J., Fujiki, M. and Takemoto, A. (2007) Facile, Efficient Functionalization of Polyolefins via Controlled Incorporation of Terminal Olefins by Repeated 1,7-Octadiene Insertion. Journal of the American Chemical Society, 129, 14170-14171. http://dx.doi.org/10.1021/ja076633w

[36] Naga, N., Shiono, T. and Ikeda, T. (1999) Cyclopolymerization of 1,7-Octadiene with Metallocene/Methylaluminoxane. Macromolecular Chemistry and Physics, 200, 1466-1472. http://dx.doi.org/10.1002/(SICI)1521-3935(19990601)200:6<1466::AID-MACP1466>3.0.CO;2-N

[37] Apisuk, W. and Nomura, K. (2014) Efficient Terpolymerization of Ethylene and Styrene with 1,7-Octadiene by Aryloxo Modified Half-Titanocenes-Cocatalyst Systems: Efficient Introduction of the Reactive Functionality. Macromolecular Chemistry and Physics, Early View. http://dx.doi.org/10.1002/macp.201400143

[38] Itagaki, K. and Nomura, K. (2009) Efficient Synthesis of Functionalized Polyolefin by Incorporation of 4-Vinylcyclohexene in Ethylene Copolymerization Using Half-Titanocene Catalysts. Macromolecules, 42, 5097-5103. http://dx.doi.org/10.1021/ma900732k

[39] Nomura, K. and Itagaki, K. (2005) Efficient Incorporation of Vinylcylohexane in Ethylene/Vinylcyclohexane Copolymerization Catalyzed by Nonbridged Half-Titanocenes. Macromolecules, 38, 8121-8123. http://dx.doi.org/10.1021/ma051439k

[40] Wang, W., Fujiki, M. and Nomura, K. (2005) Copolymerization of Ethylene with Cyclohexene (CHE) Catalyzed byNonbridged Half-Titanocenes Containing Aryloxo Ligand: Notable Effect of Both Cyclopentadienyl and Anionic Donor Ligand for Efficient CHE Incorporation. Journal of the American Chemical Society, 127, 4582-4583. http://dx.doi.org/10.1021/ja050274s

[41] Apisuk, W., Kitiyanan, B., Kim, H.J., Kim, D.H. and Nomura, K. (2013) Introduction of Reactive Functionality by the Incorporation of Divinylbiphenyl in Ethylene Copolymerization with Styrene or 1-Hexene Using Aryloxo-Modified Half-Titanocenes and MAO Catalysts. Journal of Polymer Science Part A: Polymer Chemistry, 51, 2581-2587. http://dx.doi.org/10.1002/pola.26639

[42] Chung, T.C. and Dong, J.Y. (2001) A Novel Consecutive Chain Transfer Reaction to p-Methylstyrene and Hydrogen during Metallocene-Mediated Olefin Polymerization. Journal of the American Chemical Society, 123, 4871-4876. http://dx.doi.org/10.1021/ja0039280

[43] Caporaso, L., Iudici, N. and Oliva, L. (2006) A Novel Route to Graft-Copolymers with Tailored Structures for the Compatibilization of Polymeric Blend. Macromolecular Symposia, 234, 42-50. http://dx.doi.org/10.1002/masy.200650207

[44] Apisuk, W., Suzuki, N., Kim, H.J., Kim, D.H., Kitiyanan, B. and Nomura, K. (2013) Efficient Terpolymerization of Ethylene and Styrene with $\alpha$-Olefins by Aryloxo-Modified Half-Titanocene-Based Catalysts and Cocatalyst Systems. Journal of Polymer Science Part A: Polymer Chemistry, 51, 2565-2574. http://dx.doi.org/10.1002/pola.26637

[45] Liu, J. and Nomura, K. (2008) Efficient Functional Group Introduction into Polyolefins by Copolymerization of Ethylene with Allyltrialkylsilane Using Nonbridged Half-Titanocenes. Macromolecules, 41, 1070-1072. http://dx.doi.org/10.1021/ma800031h

[46] Byun, D.J., Shin, S.M., Han, C.J. and Kim, S.Y. (1999) Chain Transfer Reaction in Metallocene Catalyzed Ethylene Copolymerization with Allyltrimethylsilane. Polymer Bulletin, 43, 333-340. http://dx.doi.org/10.1007/s002890050619

[47] Stoebenau III, E.J. and Jordan, R.J. (2006) Nonchelated $d^{0}$ Zirconium-Alkoxide-Alkene Complexes. Journal of the American Chemical Society, 128, 8162-8175. http://dx.doi.org/10.1021/ja0575225

[48] Nomura, K., Kakinuki, K., Fujiki, M. and Itagaki, K. (2008) Direct Precise Functional Group Introduction into Polyolefins: Efficient Incorporation of Vinyltrialkylsilanes in Ethylene Copolymerizations by Nonbridged Half-Ttitanocenes. Macromolecules, 41, 8974-8976. http://dx.doi.org/10.1021/ma8020757

[49] Kakinuki, K., Fujiki, M. and Nomura, K. (2009) Copolymerization of Ethylene with $\alpha$-Olefins Containing Various Substituents Catalyzed by Half-Ttitanocenes: Factors Affecting the Monomer Reactivities. Macromolecules, 42, 45854595. http://dx.doi.org/10.1021/ma900576v 
Scientific Research Publishing (SCIRP) is one of the largest Open Access journal publishers. It is currently publishing more than 200 open access, online, peer-reviewed journals covering a wide range of academic disciplines. SCIRP serves the worldwide academic communities and contributes to the progress and application of science with its publication.

Other selected journals from SCIRP are listed as below. Submit your manuscript to us via either submit@scirp.org or Online Submission Portal.
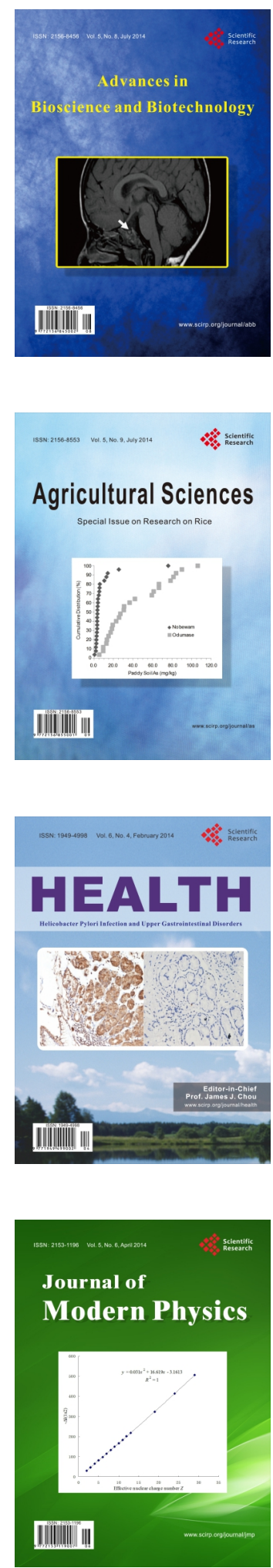
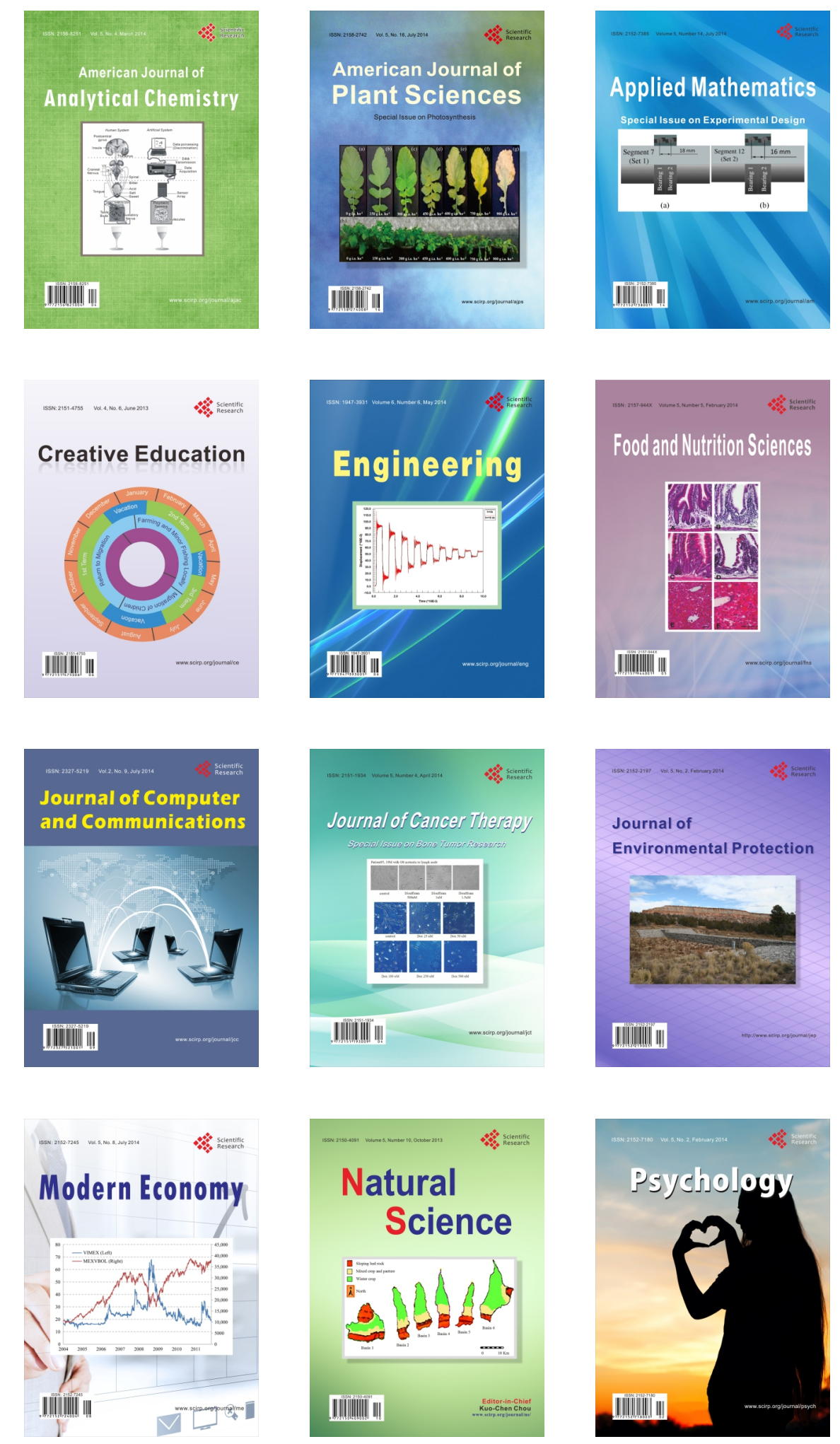